\title{
Gamification: The effect on student motivation and performance at the post-secondary level
}

\author{
Meaghan C. Lister \\ Holland College
}

\begin{abstract}
Computer games are increasingly part of the daily activities of Canadian students of all ages, and have been shown to support student motivation and learning however can be challenging to implement in the classroom. Gamification involves incorporating elements of computer games such as points, leaderboards, and badges into non-game contexts in order to take advantage of the motivation provided by a game environment. An analysis of the literature was conducted to determine to what extent gamification supports student achievement and motivation among college level students. The findings from the analysis revealed that points, badges and achievements, leaderboards and levels are the most commonly implemented form of gamification. Incorporating gamification elements into post-secondary environments can motivate students and support student achievement in post-secondary environments. Increased class attendance and participation, which is positively correlated with improved student performance, was seen as a result of gamification. This is significant, as colleges and universities strive to attract, retain, and engage digitally savvy students who are increasingly demanding engaging, technologically rich, learning environments
\end{abstract}

Keywords: gamification, post-secondary, education, motivation, performance, student achievement, points, leaderboards, badges

Today's classrooms are filled with pedagogy that is "stale, bland, and almost entirely stuff from the past" (Prensky, 2005, p. 62); however, today's students are technology savvy and expect to be engaged. Students attending post-secondary institutions, such as Holland College, are comfortable using computers and expect to utilize computers as part of their program. The 2013 New Student Survey at Holland College (completed by 1196 students) indicated that $50 \%$ of first-year students anticipated access of $50 \%$ or more of their course materials through the Internet, with an additional $14 \%$ expecting to access $40-50 \%$ of their course materials via the Internet. Eighty-nine percent of first-year students reported owning laptops, and being comfortable using the Internet to access course grades, assignments and tests. An additional $85 \%$ of students reported owning a smartphone (Gordon Ellis, personal communication, October 6, 2014). Educators are looking for methods to integrate technology in classrooms in order to engage learners. The purpose of this research is to determine what impact the use of gamification has on student motivation and achievement at the post-secondary level. 
Many Canadians play video games on a regular basis with $90 \%$ of $6-17$-year-olds and $59 \%$ of $18-34$ year-olds reported having played a computer game within the last four weeks (Entertainment Software Association of Canada, 2013). According to the 2010 Health Behaviour in School-Aged Children survey conducted by the World Health Organization, Canadian children aged $10-16$ years spend an average of one hour and 51 minutes playing video games each day (Active Healthy Kids Canada, 2014). The average age of a Canadian video game player is 31 years old (Entertainment Software Association of Canada, 2013). This is consistent with the average age of Atlantic Canada community college students, which is age 30 (Economic Modeling Specialists Intl., 2014). Both males and females play video games, with $54 \%$ of Canadian gamers being male, and 46\% female (Entertainment Software Association of Canada, 2013); these statistics are similar to the demographics of Atlantic Canada community colleges, where $53 \%$ of students are male, and $47 \%$ are female (Economic Modeling Specialists Intl., 2014). Of adults aged $18-34$ years, $40 \%$ reported playing educational games, including puzzles or word games, and games that challenge mental ability (Entertainment Software Association of Canada, 2013).

A game is a "rule-based environment that is responsive to the player's actions, offers an appropriate challenge to the player, and keeps a cumulative record of the player's actions" (Mayer \& Johnson, 2010, p. 244), while an educational computer game is a technology-supported game that is intended to result in a desirable change in the player's knowledge (Goehle, 2013; Mayer \& Johnson, 2010). Educational games serve the primary purpose of being a game, and a secondary goal of teaching something (Goehle, 2013). Games have clear goals or objectives which are divided into "shortterm achievable goals that give a seamless progression to players by providing frequent rewards that act as external motivators" (de-Marcos, Dominguez, Saenz-de-Navarrete \& Pages, 2014, p. 82).

Games have been shown to be effective in promoting learning (Annetta, Minogue, Holmes, \& Cheng, 2009; Barab, Thomas, Dodge, Carteaux, \& Tuzun, 2005; de Freitas, 2006; Ke, 2009; Liu et al., 2014; Moreno, 2012; Papastergiou, 2009; Van Eck, 2006), and are more motivational for students than non-gaming teaching methods (Barab et al., 2005; Batson \& Feinberg, 2006; de Freitas, 2006; Papastergiou, 2009). Games have been shown to be effective for learning "partly because learning takes place within a meaningful context" (Van Eck, 2006, p. 18), which allows for application and practice. Effective games must be "motivating, addictive, and provide encouragement through very short-term goals, so that the player can fail and try again until they succeed" (O’Donnell, Gain, \& Marais, 2013, p. 242). Van Eck (2006) recommends that commercially available games be identified and incorporated into the classroom for learning due to the cost-effectiveness and quality of commercially available games; however, identifying computer games that match curriculum and learning outcomes (Annetta et al., 2009; de Freitas, 2006; Tüzün, 2007) and fit within the time restrictions for classroom delivery is challenging (Gros, 2007; Tüzün, 2007). Designing games with relevant backstories to accompany the game environment is also a challenging task (Tüzün, 2007). 
One solution to overcome the challenges associated with incorporating commercially available computer games into the classroom may be the use of gamification (Muntean, 2011). Gamification involves selecting elements of games, and using these to create a game-like environment in a non-game context (Deterding et al., 2011; de-Marcos et al., 2014; Dominguez et al., 2013; Giannetto, Chao, \& Fontana, 2013; Goehle, 2013; Hanus \& Fox, 2015; Mekler et al., 2013b; Muntean, 2011; O’Donnell et al., 2013; Prince, 2013; Pedreira et al., 2014; Turner, Dieksheide, \& Anderson, 2013; Watson, Hancock, \& Mandryk, 2013) to increase user experience and engagement (Apostol, Zaharescu, \& Alexe, 2013; Dominguez et al., 2013; Pedreira et al., 2014; Turner et al., 2013). "Gamification desires to combine intrinsic motivation with an extrinsic one in order to raise motivation and engagement" (Montean, 2011, p. 326). Typically, these game elements include items such as points, leaderboards, and badges (Barata, Gama, Jorge \& Goncalves, 2013; Mekler et al., 2013b), however, game elements also can include avatars, three-dimensional environments, feedback, ranks, levels, competition, communication systems, and time pressures (Deterding et al., 2011).

Gamification has been used in a variety of settings, including healthcare, business, education, and productivity (Barata et al., 2013; Muntean, 2011; Pedreira et al., 2014). For example, Khan Academy rewards users for watching videos and solving math problems with points and badges (Barata et al., 2013; Haaranen, Ihantola, Hakulinen, \& Korhonen, 2014) and Fitocracy uses gamification to motivate users to be more physically active (Barata et al., 2013; Goehle, 2013). The purpose of this research paper is to explore the effects of gamification on student motivation and performance at the postsecondary level.

Gamification's impact on student motivation and performance is an important topic, as there has been increased interest in gamification (Hanus \& Fox, 2015) at the college level. Lambton College in Sarnia, Ontario, has recently announced intentions to incorporate gamification into its curriculum to better reach mobile-savvy students and increase student engagement. The college is now able to design curricula that include avatars and scoreboards (Kloet, 2014). Fanshawe College in London, Ontario, is using gamification elements (e.g., goals, rules, and feedback systems) to engage children and adults in improving their literacy skills (Beach, n.d.). Ensuring students are engaged in their learning in post-secondary environments is critical as student engagement "is positively related to academic outcomes as represented by first year student grades and by persistence between the first and second year of college" (Kuh, Cruce, Shoup, Kinzie, 2008, p.555).

\section{Organization of the paper}

This paper begins with a Methods section that describes how I conducted the analysis. The Findings section reports the themes identified through the analysis of the 19 studies including common elements of gamification, motivation effectiveness and impact on performance. The Discussion examines the results in more detail by assessing, critiquing, 
interpreting and evaluating the findings of the 19 studies, exploring the drawbacks of gamification, and considerations for pedagogical practice. The Conclusion highlights the primary findings with respect to the effect of gamification on learner motivation and achievement in post-secondary environments, and presents implications for practice and limitations of the study.

\section{Methods}

The 19 sources were selected from peer-reviewed journals and conference proceedings. The analysis only included sources with the word gamification or game-like as part of the title or abstract. The publication dates for the studies selected ranged from 2008 to 2015. Studies were identified using database searches of ERIC and EBSCO, as well as Google Scholar using relevant key words. The following keywords were used separately or in combination during this search: gamification and game-based learning. The table of contents of refereed open-access electronic journals that are specifically concerned with educational technology were reviewed for additional studies. The search was not limited to specific dates although preference was given to more recent research.

With the exception of one study, all of the studies used a mixed methods approach that combined both qualitative and quantitative methods to collect and analyze data. In all but one of the studies (Abramovich et al., 2013), research was conducted in a college or university environment.

As shown in Table 1, below the number of participants in the studies ranged from 14 to 371 with five studies (Abramovich et al, 2013; Charles et al., 2011; Gåsland, 2011; Meyer, 2008; O'Donovan, Gain \& Marais, 2013) having fewer than 50 participants.

The purpose of the analysis was to identify similarities, differences, and patterns, and to search for common themes on the effect of gamification on student motivation and performance in post-secondary students. A qualitative meta-analysis was conducted to "synthesize the theories, methods, and findings of both qualitative and quantitative" (Ke, 2009 , p. 6) studies related to gamification. A qualitative meta-analysis "is an approach towards formulating a complete depiction of the subject" (Ke, 2009, p.6). As part of the analysis, literature was selected based on its relevance to gamification. Once selected, the studies were numbered, alphabetized and read. Each study was re-read and annotated, focusing specifically on the data, findings, conclusions and implications that related directly to gamification (Creswell, 2012). Notes were analyzed to determine common themes and findings. 
Table 1

Summary of the descriptive characteristics of studies

\begin{tabular}{|c|c|c|c|}
\hline Author & Methodology & Participants & Demographics \\
\hline Abramovich et al, 2013 & Mixed methods & 36 & Middle school \\
\hline Barata et al., 2013 & Mixed methods & 242 & University \\
\hline $\begin{array}{l}\text { Berkling \& Thomas, } \\
2013\end{array}$ & Mixed methods & 59 & University students \\
\hline Charles et al., 2011 & Mixed methods & 18 & University students \\
\hline de-Marcos et al., 2014 & Mixed methods & 371 & $\begin{array}{l}\text { Undergraduate } \\
\text { students }\end{array}$ \\
\hline Dominguez et al., 2013 & Mixed methods & 123 & University students \\
\hline Gåsland, 2011 & Qualitative & 44 & University students \\
\hline Goehle, 2013 & Mixed methods & 60 & University students \\
\hline Hanus \& Fox, 2015 & Mixed methods & 80 & University students \\
\hline Haaranen et al., 2014 & Mixed methods & 162 & $\begin{array}{l}\text { University computer } \\
\text { science students }\end{array}$ \\
\hline $\begin{array}{l}\text { Li, Dong, Untch, \& } \\
\text { Chasteen, } 2013\end{array}$ & Qualitative & Not reported & University students \\
\hline Mayer \& Johnson, 2010 & Mixed methods & 117 & College students \\
\hline $\begin{array}{l}\text { McDaniel, Lindgren, \& } \\
\text { Friskics, } 2012\end{array}$ & Mixed methods & 200 & University students \\
\hline Mekler et al, 2013a & Mixed methods & 172 & $\begin{array}{l}\text { University } \\
\text { community members }\end{array}$ \\
\hline Mekler et al., 2013b & Mixed methods & 295 & $\begin{array}{l}\text { University } \\
\text { community members }\end{array}$ \\
\hline Meyer, 2008 & Mixed methods & 13 & Graduate students \\
\hline $\begin{array}{l}\text { O'Donovan, Gain \& } \\
\text { Marais, } 2013\end{array}$ & Mixed methods & 44 & $\begin{array}{l}\text { University computer- } \\
\text { science students }\end{array}$ \\
\hline Turner et al., 2013 & & Not indicated & University students \\
\hline Watson et al., 2013 & & $\begin{array}{l}\text { No } \\
\text { participants }\end{array}$ & $\begin{array}{l}\text { Developed } \\
\text { gamification system }\end{array}$ \\
\hline
\end{tabular}




\section{Findings}

The analyses of 19 studies reveal three main sub-themes of gamification. The subthemes that emerged from the analysis were (i) common elements of gamification, (ii) motivation effectiveness, and (iii) impact on performance.

\section{Common Elements of Gamification}

As illustrated in Figure 1, elements of gamification commonly implemented include points, leaderboards, badges and levels. O'Donnell et al. (2013) reported that badges, progress bars, leaderboards, and a storyline with accompanying visual hold the most potential for effectiveness within an educational setting.

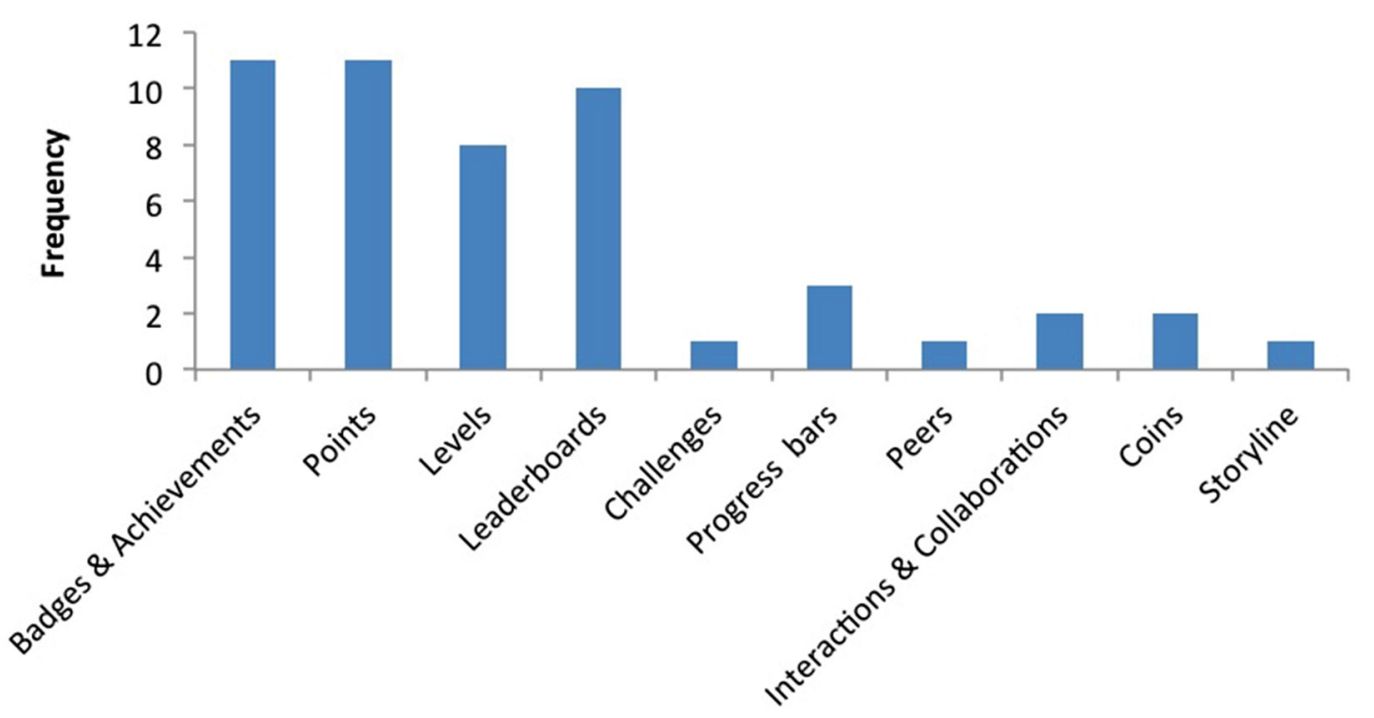

Figure 1: Frequency of gamified elements reported in studies

While many studies did not examine the effectiveness of narrative storylines in motivating students, Lawley as cited in Stott and Neustaedter (2013) caution against reducing the "complexity of well-designed games to their surface elements (i.e. badges and experience points) falls short of engaging students" (p. 1). This is not suggesting that game elements should not be incorporated into gamified learning environments, however good game design also includes instant feedback, freedom to fail, progression, and narrative stories (Stott \& Neustaedter, 2013). The elements most commonly examined in the research: (i) points, (ii) levels, (iii) badges and achievements, and (iv) leaderboards will now be examined individually in more detail. 
Table 2.

Summary of the common elements of gamification examined in studies

\begin{tabular}{|c|c|c|c|c|}
\hline Author & Points & Levels & Badges & Leaderboards \\
\hline Abramovich et al, 2013 & & & $x$ & \\
\hline Barata et al., 2013 & $x$ & $x$ & $x$ & $x$ \\
\hline Berkling \& Thomas, 2013 & $x$ & $x$ & & \\
\hline Charles et al., 2011 & $x$ & & $x$ & $x$ \\
\hline de-Marcos et al., 2014 & & & $x$ & $\mathrm{x}$ \\
\hline Dominguez et al., 2013 & $\mathrm{X}$ & & $x$ & $\mathrm{x}$ \\
\hline Gåsland, 2011 & $x$ & & & \\
\hline Goehle, 2013 & & $\mathrm{x}$ & $x$ & \\
\hline Hanus \& Fox, 2015 & & & $x$ & $\mathrm{x}$ \\
\hline Haaranen et al., 2014 & & & $x$ & \\
\hline Li, Dong, Untch, \& Chasteen, 2013 & $x$ & $\mathrm{x}$ & & $\mathrm{x}$ \\
\hline Mayer \& Johnson, 2010 & $x$ & $x$ & & \\
\hline McDaniel, Lindgren, \& Friskics, 2012 & & & $x$ & $\mathrm{x}$ \\
\hline Mekler et al, 2013a & $x$ & & & \\
\hline Mekler et al., 2013b & $x$ & $x$ & & $x$ \\
\hline Meyer, 2008 & $x$ & & & \\
\hline O’Donovan, Gain \& Marais, 2013 & $x$ & & $x$ & $\mathrm{x}$ \\
\hline Turner et al., 2013 & & $x$ & $x$ & $\mathrm{x}$ \\
\hline Watson et al., 2013 & & $\mathrm{X}$ & & \\
\hline
\end{tabular}

\section{Points}

Research reviewed in this area examined studies that focused solely on the inclusion of points to motivate and engage students, as well as on studies that examined the effectiveness of points in combination with other elements of gamification. The majority of studies found that points provided instant feedback that students found motivating. Many researchers also identified the fact that points must be used in combination with other elements of gamification in order to be effective in motivating students.

As shown in Table 2, points were examined in 11 of 19 studies (Barata et al., 2013; Berkling \& Thomas, 2013; Charles, Charles, McNeill, Bustard, \& Black, 2011; Dominguez et al., 2013; Gåsland, 2011; Li et al., 2013; Mayer \& Johnson, 2010; Mekler et al., 2013a; 
Mekler et al., 2013b; Meyer, 2008; O'Donovan, Gain \& Marais, 2013) and are the basis of many gamified elements such as leaderboards and levels (Mekler et al., 2013a). Points can be awarded for a wide variety of tasks such as completing quizzes, attending lectures, taking part in class exercises, solving puzzles, creativity in assignments (Charles et al., 2011; O'Donnell et al., 2013), completing practice questions, or correct answers (Mekler et al., 2013a).

Mekler et al. (2013a) discovered that awarding points was effective in increasing intrinsic motivation. Gåsland (2011) also determined that students found a points-based gamification system to be somewhat motivating and quite engaging. This motivation may be due to the fact that points provide learners with instant feedback and recognition for the completion of an activity or task (Mekler et al., 2013a), which is consistent with the findings of O'Donnell et al. (2013), who found that immediate feedback was a "key aspect of gamification, in that it solidifies the connection between doing right and being rewarded for it” (p. 246).

Not all research reported a positive relationship between points and student motivation and performance. Meyer (2008) examined the impact of points on the quality of postings in an online discussion forum by graduate students and found that nine of 13 students reported that points had no effect on the quality of their postings. Abramovich et al. (2013) found that the prior experiences of students impacted the effectiveness of gamification; therefore, in the case of the research by Meyer (2008), one reason for his results may be that graduate students are already motivated and, therefore, less motivated by points.

\section{Levels}

All of the studies reviewed that examined the use of levels to motivate and engage students used levels in combination with other elements of gamification. One of the key elements that makes gamification successful is ensuring appropriate scaffolding, progression and sequencing through content and activities, in a manner which does not leave the learner frustrated, but instead ensures an appropriate level of challenge (Stott \& Neustaedter, 2013). Levels allow a game to be divided into small, separate, attainable pieces and moving up to the next level is often a strong motivator of continued effort (Gåsland, 2011).

As shown in Table 2, levels were reported in eight of 19 studies (Barata et al., 2013; Berkling \& Thomas, 2013; Goehle, 2013; Li et al., 2013; Mayer \& Johnson, 2010; Mekler et al., 2013b; Turner et al., 2013; Watson et al., 2013). To implement levels, users must gain points. After gaining a certain predetermined number of points, users move up a level. Generally, "levelling up" confers some sort of in-game benefit (Goehle, 2013). Levels positively impact student motivation and engagement. Goehle (2013) found that $93 \%$ of students kept track of their levels and achievements while $89 \%$ actively worked to obtain achievements. As a result of this, course designers may want to ensure that there are clear criteria available for students to review about how to earn higher levels. If 
points are used to determine "levelling up", course designers could indicate the number of points needed before attaining the subsequent level.

\section{Badges / Achievements}

Mixed results were found with respect to the impact of badges and achievements on student motivation and performance at the post-secondary level. Some research found badges and achievements supported student engagement, while other research found there was no impact or a negative impact on student engagement and motivation.

Badges or achievements are symbolic awards given to students for completing "any type of skill, knowledge or achievement" (Abramovich, Schunn, \& Higashi, 2013, p. 218) that can be displayed by learners to "let others know of their mastery or knowledge" (Abramovich et al., 2013, p. 218) and typically have specifically stated criteria (Ahn, Pellicone, \& Butler, 2014; Dominguez et al., 2013; Hanus \& Fox, 2015). Badges are a common element of gamification introduced into courses, reported in 11 of 19 studies that are listed in Table 2 (Abramovich et al., 2013; Barata et al., 2013; Charles et al., 2011; de-Marcos et al., 2014; Dominguez et al., 2013; Goehle, 2013; Hanus \& Fox, 2015; Haaranen et al., 2014; McDaniel et al., 2012; O'Donovan et al., 2013; Turner et al., 2013). Badges introduce a social element to courses by allowing students to identify with other learners who are working towards the same goals (O'Donnell et al., 2013; Turner et al., 2013). If social sharing is built into courseware, then learners can share their badges on social media (Turner et al., 2013) gaining additional recognition for their achievements from family and friends. Users typically have access to review the badges they have earned and to review the requirements to obtain new badges (Hanus \& Fox, 2015).

There are mixed results with respect to the impact of badges on learner motivation and performance (Abramovich et al., 2013). McDaniel et al. (2012) found that badges and achievements "had the motivational effect that was desired" (p.3). Similarly, Geohle (2013) reported that learners felt rewarded for completing their homework and appreciated the extra acknowledgement obtained when they were awarded with a badge or an achievement. Haaranen et al. (2014) stated that approximately one-third of college students were motivated by the badges, one-third were indifferent towards the badges, and the remaining one-third did not find the badges motivating. Contrary to this, Hanus and Fox (2015) found that students in the gamified version of a university course, which incorporated badges and leaderboards, were less motivated and had lower final exam scores than students enrolled in the non-gamified version of the course.

Not all learners are motivated by the same types of badges (Ahn et al., 2014). Abramovich et al. (2013) found that there was a difference in badge acquisition patterns for learners with different levels of prior knowledge; low-performing students were motivated by badges awarded for participation, while high-performing students were motivated by badges awarded for skill acquisition. 


\section{Leaderboards}

Leaderboards are a commonly used gamification element, and there are mixed results with respect to the impact of leaderboards on motivation of students at the post-secondary level. For some students, leaderboards provide motivation, while other students dislike the element of competition that leaderboards introduce into the learning environment. For competitive students, leaderboards provide instant feedback and allow learners to continuously strive to improve their place in the rankings.

Leaderboards were tested in 10 of 19 studies (Barata et al., 2013; Charles et al., 2011; de-Marcos et al., 2014; Dominguez et al., 2013; Hanus \& Fox, 2015; Li et al., 2013; McDaniel et al., 2012; Mekler et al., 2013b, O'Donovan et al., 2013; Turner et al., 2013) examined as depicted in Table 2. Leaderboards create competition and a sense of belonging to a similar-minded group (O'Donnell et al., 2013). They allow learners to compare performance to that of other students (Charles et al., 2011; O'Donnell et al., 2013). Leaderboards can be based on a points system, on how many achievements learners have obtained, or a learner's percentage progress towards a final end goal (Dominguez et al., 2013).

Leaderboards are similar to the sticker charts used for years by teachers in classrooms, but have the distinct advantage of allowing students to access the leaderboard outside of the classroom (Hanus \& Fox, 2015). This allows students to spend as much time as desired comparing their performance to others without anyone else knowing "they are engaged in such deep social comparison" (Hanus \& Fox, 2015, p. 154).

The impact of leaderboards on motivation varies among learners. Some research has shown that leaderboards are a "source of motivation because students can see their work publically and are instantly recognized" (Dominguez et al., 2013, p. 391). In addition, leaderboards have been shown to inspire "participants to maintain their performance for longer, compared to points and control groups" (Mekler et al., 2013b, p.70). Other research has shown that for students who do not enjoy competition, leaderboards can negatively impact student motivation (Dominguez et al, 2013; Hanus \& Fox, 2015). Charles et al. (2011) determined that the minority of students "expressed discontent with the competitive nature of the feedback" (p. 644).

\section{Motivation Effectiveness}

As shown in Table 3, below, 12 of 19 studies reported a positive impact on student motivation as a result of gamification (Abramovich et al, 2013; Barata et al., 2013; Charles et al., 2011; De-Marcos et al., 2014; Dominguez et al., 2013; Gåsland, 2011; Goehle, 2013; Li et al., 2013; McDaniel et al., 2012; Mekler et al., 2013a; Mekler et al., 2013b; O'Donovan et al., 2013). A small percentage (10\%) of studies reported no impact or negative impacts on student motivation (Berkling \& Thomas, 2013; Hanus \& Fox, 2015). Additionally, some studies reported mixed results with respect to motivation (Dominguez 
et al., 2013; Haaranen et al., 2014; Meyer, 2008). Meyer (2008) indicated that students reported that gamification did not affect their motivation to post or quality of post in a discussion forum; however, a small percentage (15\%) of students did report a positive impact as a result of the introduction of point-based rewards. Similarly, Dominguez et al. (2013) reported that $31 \%$ of students found gamified environments motivating; however, $62 \%$ of learners reported that the traditional activities were more motivating.

Table 3

Summary of the motivational effectiveness of gamification reported in studies

Author

Motivating Demotivating Mixed Impact on

Motivation

Abramovich et al, 2013

$x$

Barata et al., 2013

$\mathrm{X}$

Berkling \& Thomas, 2013

$x$

Charles et al., 2011

$X$

de-Marcos et al., 2014

$\mathrm{X}$

Dominguez et al., 2013

$x$

$x$

Gåsland, 2011

$x$

Goehle, 2013

$x$

Hanus \& Fox, 2015

$x$

Haaranen et al., 2014

$\mathrm{X}$

$\mathrm{Li}$, Dong, Untch, \& Chasteen,

$x$ 2013

Mayer \& Johnson, 2010

McDaniel, Lindgren, \& Friskics,

$X$

2012

Mekler et al, 2013a

$x$

Mekler et al., 2013b

$x$

Meyer, 2008

$x$

O’Donovan, Gain \& Marais, 2013

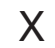

Turner et al., 2013

Watson et al., 2013 


\section{Impact on Performance}

The impact on learning and student performance was difficult to ascertain, as many studies did not report the effects on student performance. Of studies reporting results related to academic performance, the results are mixed. Barata et al. (2013) determined there was an increase in the number of students attaining the highest

grades, as well as a decrease in the difference between the lowest and highest student grades. This is consistent with the findings of Mekler et al. (2013b), who found that gamification "significantly increased performance" (p. 66). Contrary to this finding, Hanus \& Fox (2015) and de-Marcos et al. (2014) found that learners who participated in the gamified environment had lower exam scores, while Goehle (2013) found little evidence of impact either positive or negative on student performance.

Three studies reported increased student participation (Barata et al., 2013; Charles et al., 2011; Li et al., 2013) and lecture attendance (Barata et al., 2013; Charles et al., 2011) as a result of gamification. Increased student attendance has been shown to correlate positively with improved student performance (Adegoke, Salako, \& Ayinde, 2013). Mayer \& Johnson (2010) reported that students learned faster and were better able to transfer knowledge. Similarly, Charles et al. (2011) determined that "poor levels of engagement lead to non-progression within a course" (p. 646) and that when gamification was introduced into a first year computer course, there was a " $12.9 \%$ reduction in the number of failures" (p. 647).

\section{Discussion}

Twelve out of 19 studies reported a positive impact on student motivation as a result of gamification (Abramovich et al, 2013; Barata et al., 2013; Charles et al., 2011; deMarcos et al., 2014; Dominguez et al., 2013; Gåsland, 2011; Goehle, 2013; Li et al., 2013; McDaniel et al., 2012; Mekler et al., 2013a; Mekler et al., 2013b; O'Donovan et al., 2013). Elements of gamification such as points, badges, leaderboards and levels provide feedback and encouragement to learners. This immediate feedback can help motivate students to practice (Shute, 2008) and is a key element of gamification (O'Donnell et al., 2013). The game-like environment created by introducing elements of gamification into post-secondary courses is reminiscent of video games and can create a sense of novelty and help to engage students who are technology savvy (Dominguez et al., 2013; Goehle, 2013)

Elements of gamification contribute to increased engagement and motivation for some students; however, these elements cannot stand alone (Deterding, 2014; Gåsland, 2011; Mekler et al., 2013b). Good game design also includes careful scaffolding and progression of content, and captivating and relevant narrative stories (Apostol et al., 2013; Erenli, 2013; Gåsland, 2011; Stott \& Neustaedter, 2013). It provides the freedom for learners to fail and try again (Stott \& Neustaedter, 2013). These are not unlike the 
characteristics of engaging classroom teaching (Stott \& Neustaedter, 2013).

\section{Additional Benefits of Gamification}

In addition to the impact on student motivation and engagement (Barata et al., 2013; Goehle, 2013; Li et al., 2013), gamification conferred a number of other benefits, including student feelings of acknowledgement (Charles et al., 2011; Goehle, 2013) and accomplishment. Barata et al. (2013) found that "students were more proactive and participative" in a gamified course while other research found that gamification gave learners something else to work towards besides simply a grade (Goehle, 2013). Charles et al. (2011) observed that learners appeared "more motivated to complete voluntary tasks" such as preparation for class, attendance and participation (p. 645).

\section{Drawbacks of Gamification}

Not all learners are motivated by or benefit from gamification (Haaranen et al., 2014; Whitton, 2012). In fact, the "entertainment features of games may distract the player from the academic content of the game, and reduce the players' efforts to process the material more deeply" (Mayer \& Johnson, 2010, p. 248). It is important to ensure that the introduction of competition through gamification does not encourage carelessness among students (Haaranen et al., 2014) and is not demotivating for students (Charles et al., 2011; Dominguez et al., 2013; Glover, 2013; Whitton, 2012). Haaranen et al. (2014) reported that some learners have strong negative feelings about the use of badges in a college course. For this reason, Haaranen et al. (2014) recommended that options be built into gamification systems that would allow learners to turn off elements such as badges. Differences have been determined to exist between the motivation levels of students who play video games regularly versus students who do not: specifically, students who play video games were more motivated by gamification elements (Goehle, 2013).

\section{Considerations for pedagogical practice}

Games are motivating as a result of their impact on cognitive, emotional, and social areas of players (Annetta et al., 2009; Lee \& Hammer, 2011), therefore in designing an implementation plan for gamified elements, course designers should consider how they appeal to each of these areas. Good gamification design should have "special meaning for the user, the ability to inspire the user to master the topic and it should be autonomous, by providing a feeling of free choice" (O'Donovan, Gain \& Marais, 2013, p. 244).

Social aspects can be incorporated into course design by allowing learners the opportunity to share badges and achievements earned through social network systems (Haaranen et al., 2014). Sharing accomplishments with friends, family and peers, "increases the amount of weight the achievements and levels carry with the student" (Goehle, 2013, p. 241). Collaborative or group achievements and badges can also be built into course 
design, allowing learners to work together to attain their goals (Goehle, 2013), further enhancing social interaction.

Emotionally, gamification impacts learners through feelings of success and failure, as well as frustration and anxiety (Dominguez et al., 2013). A well-designed gamification environment allows learners to experience all of these emotions. High levels of frustration or anxiety are best avoided by carefully designing tasks and learning activities with appropriate levels of challenge (Dominguez et al., 2013). Careful sequence of the progression of learning helps to ensure that learners do not experience high levels of frustration (Stott \& Neustaedter, 2013).

One of the motivations behind playing games is that they are fun. Gamification is designed to introduce elements of play into learning; however, poorly designed gamification can result in learners being forced to play (Deterding, 2014; Prince, 2013), which is not fun. One of the challenges associated with using gamification is that the introduction of game elements alone does not make a non-game context fun (Deterding, 2014; Gåsland, 2011) and the addition of points, leaderboards, and levels is "not sufficient to make non-game contexts more engaging" (Mekler et al., 2013b, p. 71) nor do these elements increase intrinsic motivation. The addition of narrative stories to the gamified environment has been shown to be effective in motivating and engaging learners (Apostol et al., 2013; Erenli, 2013; Gåsland, 2011; Stott \& Neutaedter, 2013). "A story links the tasks together to create a cohesive whole" (Villagrasa \& Duran, 2013, p.430). While stories can be woven into a course, this requires a lot of effort on the part of the course designer (Gåsland, 2011) to create a narrative that is appropriate and engaging for the learner, as well as tailored to the course content. Course instructors and instructional designers must carefully consider how to best implement gamified elements into coursework to ensure enhanced engagement and motivation.

\section{Conclusion}

Consistent with the findings of Humari, Koivisto, and Sarsa (2014), the majority of the research examined in this study (Abramovich et al, 2013; Barata et al., 2013; De-Marcos et al., 2014; Charles et al., 2011; Dominguez et al., 2013; Gåsland, 2011; Goehle, 2013; Li et al., 2013; McDaniel et al., 2012; Mekler et al., 2013a; Mekler et al., 2013b; O'Donovan et al., 2013) reported that the inclusion of gamified elements such as points, badges, achievements, leaderboards, and levels resulted in positive effects on learner motivation among post-secondary students. On account of their beneficial influence, implementation of gamified environments into post-secondary classrooms is worthy of consideration; however, course instructors and instructional designers ought to consider the profiles of the learners and ensure that steps are taken to mitigate any negative impacts of gamification on learners who do not find gamification beneficial.

There is limited research upon which to draw a conclusion about the impact of gamification on student academic success and performance. Increased class participation (Barata et 
al., 2013; Charles et al., 2011; Li et al., 2013) and class attendance (Barata et al., 2013; Charles et al., 2011) was seen as a result of gamification and is positively correlated with improved student performance (Adegoke, Salako, \& Ayinde, 2013). In two studies, there was an increase in the number of students attaining high grades (Barata et al., 2013; Mekler et al., 2013b) and a reduction in the gap between the lowest and highest student grades (Barata et al., 2013). In one study, Charles et al. (2011) reported that there was a $12.9 \%$ reduction in the number of learners who failed a first year computer course.

\section{Challenges for implementation in post-secondary environments}

Gamification impacts students differently: as illustrated in Table 3, some find gamification very motivating and engaging, while others do not. Some research has shown that weaker students may be more motivated by a gamified environment than stronger students (Charles et al., 2011). Glover (2013) cautions course designers to ensure that the competitive nature of gamification does not discourage less competitive learners from engaging. Course instructors and instructional designers must carefully consider the learning profile of the audience, including the prior knowledge levels (Abramovich et al., 2013), when considering implementing gamification into courses.

To implement gamification successfully requires a large investment in the design and setup of the gamified environment (Dominguez et al., 2013). Planning is required to develop appropriate point systems, challenges, badges, and achievements, which allow learners to progress through the course in a manner that gives them free choice, but also guides them. Providing immediate feedback and allowing students to "level up" requires a large investment of time to ensure that there is a close match between the course content, delivery schedule and the gamified environment (Villegrasa \& Duran, 2013). Because of the amount of planning and effort required to implement gamification successfully, colleges and universities may consider hiring instructional designers to support faculty in implementing game elements into courses (Van Eck, 2006).

Usability and technical issues can negatively impact the perception of learners and the usefulness of a gamification system (Dominguez et al., 2013; Gåsland, 2011). Technical issues can cause frustration and a negative perception of the gamified environment by learners. A thorough testing procedure ought to be used to ensure that technical problems do not impact student motivation (Dominguez et al., 2013).

\section{Limitations}

Several limitations arose, affecting the results of the findings. As this is a relatively new concept, there is limited research available on the topic of gamification. Some of the studies examined had small sample sizes, thus limiting the scope of the results and the generalizability of the findings (Abramovich et al, 2013; Charles et al., 2011; Gåsland, 2011; Meyer, 2008; O'Donovan, Gain \& Marais, 2013). In addition, many studies were discarded from the findings due to a lack of empirical evidence and participants in 
the research. In most cases, the experimental time frames were very short, making it difficult to determine the long-term effects of the use of gamification in post-secondary environments.

There are many different elements that can be used in a creating a gamified learning environment; some of the studies examined one element, while others examined the combined effects of several elements. It is difficult to ascertain the impact of individual elements from studies that examined combined effects, and, therefore, attribute elements to success or lack of success of a gamified environment. Further research on the individual elements and their impact on student motivation and learning is required. 


\section{References}

Abramovich, S., Schunn, C., \& Higashi, R. (2013). Are badges useful in education?: It depends upon the type of badge and expertise of learner. Educational Technology Research and Development, 61(2), 217 - 232.

Active Healthy Kids Canada (2014). Is Canada in the Running? The 2014 Active Healthy Kids Canada Report Card on Physical Activity for Children and Youth. Retrieved from Active Healthy Kids website: http://www.activehealthykids.ca/ReportCard/ SedentaryBehaviours.aspx

Adegoke, B., Salako, R., Ayinde, L. (2013). Impact of attendance on students' academic performance in ICT related courses: Faculty of Engineering, Osun State Polytechnic, Iree. Journal of Education and Practice, 4(16), 95 - 98. Retrieved from www.iiste.org/Journals/index.php/JEP/article/ download/7366/7501

Ahn, J., Pellicone, A., \& Butler, B. (2014). Open badges for education: What are the implications at the intersection of open systems and badging? Research in Learning Technology, 22. doi: 10.3402/rlt.v22.23563

Annetta, L., Minogue, J., Holmes, S. \& Cheng, M. (2009). Investigating the impact of videogames on high school students' engagement and learning about genetics. Computers \& Education, 53(1), 74-85.

Apostol, S., Zaharescu, L., \& Alexe, I. (2013). Gamification of learning and educational games. Paper presented at the International Scientific Conference eLearning and Software for Education, 2, 67-72. Retrieved from http://search.proquest.com/ docview/1440877124?accountid=12378

Barab, S., Thomas, M., Dodge, T., Carteaux, R., \& Tuzun, H. (2005). Making learning fun: Quest Atlantis, a game without guns. Educational Technology, Research \& Development, 53(1), 86 - 107.

Barata, G., Gama, S., Jorge, J., \& Gonçalves, D. (2013). Improving participation and learning with gamification. Proceedings of the First International Conference on gameful design, research, and applications, 10-17. doi: $10.1145 / 2583008.2583010$

Batson, L., \& Feinberg, S. (2006). Game designs that enhance motivation and learning for teenagers. Electronic Journal for the Integration of Technology in Education, $5,34-43$. 
Beach, R. (n.d.). Teaching literacy through gamification. Fanshawe College. Retrieved from http://www.fanshawec.ca/services/research/feature-stories/teachingliteracy-through-gamification

Berkling, K., \& Thomas, C. (2013). Gamification of a software engineering course and a detailed analysis of the factors that lead to its failure. Paper presented at the 2013 International Conference on Interactive Collaborative Learning, 525-530. doi:10.1109/ICL.2013.6644642

Charles, D., Charles, T., McNeill, M., Bustard, D., \& Black, M. (2011). Game-based feedback for educational multi-user virtual environments. British Journal of Educational Technology, 42(4), 638-654. doi:10.1111/j.1467-8535.2010.01068.x

Creswell, J. W. (2012). Educational Research: Planning, conducting, and evaluating quantitative and qualitative research (4th ed.). Boston, MA: Pearson Education Inc.

Deterding, S., Dixon, D., Khaled, R., \& Nacke, L. (2011). From game design elements to gamefulness: Defining "gamification". Proceedings of the 15th International Academic MindTrek Conference, 9-15. doi:10.1145/2181037.2181040

Deterding, S. (2014): Eudaimonic Design, or: Six Invitations to Rethink Gamification. In: Fuchs, M., Fizek, S., Ruffino, P. and Schrape, N. (Eds.): Rethinking Gamification. Lüneburg: meson press, pp. 305-331. Retrieved from https:// dl.dropboxusercontent.com/u/220532/00\%20Publications/rethinkinggamification-detering-eudaimonic-design.pdf

de Freitas, S. (2006). Using games and simulations in learning. Learning, Media and Technology, 31(4), 343 - 358. doi: 10.1080/17439880601021967

de-Marcos, L., Dominguez, A., Saenz-de-Navarrete, J., \& Pages, C. (2014). An empirical study comparing gamification and social networking on e-learning. Computers \& Education, 75, 82-91.

Dominguez, A., Saenz-de-Navarrete, J., de-Marcos, L., Fernandez-Sanz, L., Pages, C., Martinez-Herraiz, J. (2013). Gamifying learning experiences: Practical implications and outcomes. Computers \& Education, 63, 380 - 392.

Economic Modeling Specialists Intl. Atlantic Provinces Community College Consortium, (2014). Demonstrating the value of the Atlantic community colleges: Analysis of the economic impact and return on investment of education. Retrieved from website: http://www.apccc.ca/news/AtIProv_Agg_MainReport_1213_Finalv2.pdf 
Erenli, K. (2011). Gamify your teaching: Using location-based games for educational purposes. International Journal of Advanced Corporate Learning, 6(2), 22-27. http://dx.doi.org/10.3991/ijac.v6i2.2960

Erenli, K. (2013). The Impact of Gamification - Recommending Education Scenarios. International Journal of Emerging Technologies in Learning (IJET), 8(2013), 1521.

Essential facts about the Canadian computer and video game industry. (2013). Entertainment Software Association of Canada. Retrieved September 15, 2014, from http://theesa.ca/wp-content/uploads/2013/10/Essential-Facts-English.pdf

Gåsland, M. (2011). Game mechanic based e-learning. Science And Technology, Master Thesis (June 2011). Retrieved October 4, 2014 from http://ntnu.divaportal.org/smash/get/diva2:441760/FULLTEXT01.

Giannetto, D., Chao, J., \& Fontana, A. (2013). Gamification in a social learning environment. Issues in Informing Science \& Information Technology, 10, 195.

Goehle, G. (2013). Gamification and web-based homework. PRIMUS: Problems, Resources, and Issues in Mathematics Undergraduate Studies, 23(3), 234-246. doi:10.1080/10511970.2012.736451

Glover, lan (2013). Play as you learn: Gamification as a technique for motivating learners. Proceedings of World Conference on Educational Multimedia, Hypermedia and Telecommunications, 1999 - 2008. Retrieved from http://shura. shu.ac.uk/7172/1/Glover_-_Play_As_You_Learn_-_proceeding_112246.pdf

Gros, Begona. (2007). Digital games in education: The design of games-based learning environments. Journal of Research on Technology in Education, 40(1), 23 - 38.

Haaranen, L., Ihantola, P., Hakulinen, L., \& Korhonen, A. (2014). How (not) to introduce badges in online exercises. SIGCSE '14 Proceedings of the 45th ACM technical symposium on Computer science education, 33 - 38. doi: $10.1145 / 2538862.2538921$

Hanus, M. \& Fox, J. (2015). Assessing the effects of gamification in the classroom: A longitudinal study on intrinsic motivation, social comparison, satisfaction, effort, and academic performance. Computers \& Education, 80(0), 152 - 161.

Hamari, J., Koivisto, J., \& Sarsa, H. (2014). Does gamification work? -- A literature review of empirical studies on gamification. Paper presented at the $201447^{\text {th }}$ Hawaii International Conference on System Sciences, 3025-3034. doi:10.1109/ HICSS.2014.377 
Ke, F. (2009). A qualitative meta-analysis of computer games as learning tools. In R. E. Ferdig (Ed.), Handbook of Research on Effective Electronic Gaming in Education (pp. 1-32), New York: IGI Global.

Kloet, J. (2014). Lambton College launches innovative gamification program as part of mobile learning initiative [Press release]. Lambton College. Retrieved from https://www.lambton.on.ca/display_news.aspx?id=2147501461

Kuh, G., Cruce, T., Shoup, R., Kinzie, J. (2008). Unmasking the effects of student engagement on first-year college student grades and persistence. The Journal of High Education, 79(5), 540-563. Retrieved from http://www.yorku.ca/retentn/ rdata/Unmaskingtheeffects.pdf

Lee, J. J., \& Hammer, J. (2011). Gamification in education: what, how, Why Bother? Definitions and uses. Exchange Organizational Behavior Teaching Journal, 15(2), $1-5$.

Li, C., Dong, Z., Untch, R. H., \& Chasteen, M. (2013). Engaging computer science students through gamification in an online social network based collaborative learning environment. International Journal of Information and Education Technology, 3(1), 72-77. doi:10.7763/IJIET.2013.V3.237 https://www.lambton.on.ca/display news.aspx?id=2147501461

Liu, M., Rosenblum, J., Horton, L., \& Kang, J. (2014). Designing science learning with game-based approaches. Computers in the Schools, 31(1-2), 84 - 102. doi: 10.1080/07380569.2014.879776

Mayer R., \& Johnson, C. (2010). Adding instructional features that promote learning in a game-like environment. Journal of Educational Computing Research, 42(3), 241 $-265$.

McDaniel, R., Lindgren, R., \& Friskics, J. (2012). Using badges for shaping interactions in online learning environments. Proceedings of the 2012 IEEE International Professional Communication Conference, 55-76.

Mekler, E., Brühlmann, F., Opwis, K., \& Tuch, A. (2013a). Disassembling gamification: The effects of points and meaning on user motivation and performance. Proceedings of the SIGCHI Conference on Human Factors in Computing Systems (CHI EA'13), 1137-1142. doi:10.1145/2468356.2468559

Mekler, E., Brühlmann, F., Opwis, K., \& Tuch, A. (2013b). Do points, levels and leaderboards harm intrinsic motivation? An empirical analysis of common gamification elements. Proceedings of the First International Conference on gameful design, research, and applications, 66-73. doi:10.1145/2583008.2583017 
Meyer, K. (2008). Do rewards shape online discussions? Journal of Interactive Online Learning, 7(2), 126 - 138.

Moreno, J. (2012). Digital competition game to improve programming skills. Educational Technology \& Society, 15(3), 288-297.

Muntean, C.I. (2011). Raising engagement in e-learning through gamification. Proceedings of the 6th International Conference on Virtual Learning. Retrieved from http://icvl.eu/2011/disc/icvl/documente/pdf/met/ICVL_ ModelsAndMethodologies_paper42.pdf

O’Donovan, S., Gain, J., \& Marais, P. (2013). A case study in the gamification of a university-level games development course. Proceedings of the South African Institute for Computer Scientists and Information Technologists Conference, (SAICSIT'13), 242 - 251. doi: 10.1145/2513456.2513469

Papastergiou, M. (2009). Digital game-based learning in high-school computer science education: Impact on educational effectiveness and student motivation. Computers and Education, 52 (1), 1- 12.

Pedreira, O., Garcia, F., Brisaboa, N., \& Piattini, M. (2014). Gamification in software engineering - A systematic mapping. Information and Software Technology. doi: 10.1016/j.infsof.2014.08.007

Prensky, M. (2005). "Engage me or enrage me": What today's learners demand. EDUCAUSE Review, 40(5), 60.

Prince, J.D. (2013) Gamification, Journal of Electronic Resources in Medical Libraries, 10(3), 162-169, doi: 10.1080/15424065.2013.820539

Shute, V. J. (2008). Focus on formative feedback. Review of Educational Research, 78(1), 153-189. doi:10.3102/0034654307313795

Stott, A. \& Neustaedter, C. (2013) Analysis of Gamification in Education, Technical Report 2013-0422-01, Connections Lab, Simon Fraser University, Surrey, BC, Canada, April. Retrieved from http://clab.iat.sfu.ca/pubs/Stott-Gamification.pdf

Turner, C., Dierksheide, J., \& Anderson, P. (2014). Learn2Mine: Data science practice and education through gameful experiences. International Journal of e-Education, e-Business, e-Management, and e-Learning, 4(3), 243 - 248.

Tüzün, H. (2007). Blending video games with learning: Issues and challenges with classroom implementations in the Turkish context. British Journal of Educational Technology, 38(3), $465-477$.

Van Eck, R. (2006). Digital game-based learning: It's not just the digital natives who are restless. EDUCAUSE Review, 41(2), 16. 
Villagrasa, S., \& Duran, J. (2013). Gamification for learning 3D computer graphics arts. Proceedings of the First International Conference on technological ecosystem for enhancing multiculturality, 429-433. doi:10.1145/2536536.2536602

Watson, D., Hancock, M., \& Mandryk, R. (2013). Gamifying behaviour that leads to learning. Proceedings of the First International Conference on gameful design, research, and applications, 87 - 90. doi: 10.1145/25830008.2583021

Whitton, N. (2012). The place of game-based learning in an age of austerity. Electronic Journal of e-Learning, 10(2), 249-256. 